\title{
HELICONS IN PLASMA SOLID-STATE WAVEGUIDE OF CYLINDRICAL CONFIGURATION
}

\author{
Yu.O. Averkov ${ }^{1,2}$, Yu.V. Prokopenko ${ }^{1,3}$, V.M. Yakovenko ${ }^{1}$ \\ ${ }^{1}$ A. Ya. Usikov Institute for Radiophysics and Electronics \\ of National Academy of Sciences of Ukraine, Kharkiv, Ukraine; \\ ${ }^{2}$ V.N. Karazin Kharkiv National University, Kharkiv, Ukraine; \\ ${ }^{3}$ Kharkiv National University of Radioelectronics, Kharkiv, Ukraine \\ E-mail:yuriyaverkov@gmail.com;prokopen@ire.kharkov.ua;yavm@ire.kharkov.ua
}

The theory of electromagnetic eigenwaves of a cylindrical plasma waveguide located in a constant longitudinal magnetic field has been created. A dispersion equation has been obtained under condition when the ratio of the collision frequency of the majority charge carriers to their cyclotron frequency is substantially less than one. It is shown there are bulk-surface helicons in a plasma waveguide. In the absence of charge-carrier collisions, their propagation is accompanied by a surface current directed parallel to the longitudinal axis of symmetry of the cylinder. Collisions of charged particles destroy the surface current and lead to the formation of additional $H$-type hybrid waves, the field localizations of which are concentrated near the side surface of the waveguide. The nonreciprocity effect of the eigenwaves, differing in the direction of propagation along the azimuthal coordinate, as well as when the direction of the external magnetic field is changed, has been discovered.

PACS: 03.50.-z, 52.40.-w, 52.59.-f, 85.45.-w

\section{INTRODUCTION}

Dielectric waveguides and resonators are widely used in modern radiophysics $[1,2]$. In this case, the dispersion of the dielectric permittivity of the waveguide structures does not demonstrate in the microwave and millimeter ranges. However, in conductive solids the dispersion properties of conductivities are known. Their presence leads to different effects. For example, the conducting media become radioparent in the microwave and millimeter ranges in strong magnetic fields, when the cyclotron frequency of the majority charge carriers is substantiality higher than their collision frequency [3 - 5]. Particular interest is studied of conducting solids in which there are plasma properties. In the physics of magnetized plasma, slow electromagnetic waves of elliptical polarization - helicons - are well known [6 10]. Their phase velocities depend on the field frequency, but do not depend on the mass of charge carriers. Such waves can be interpreted as perturbations of the force lines of a constant magnetic field, on which charged particles are strung on like a string of beads.

The goal of this work is to determine the spectrum of natural oscillations of a plasma solid-state cylinder located in a strong magnetic field, and to identify its characteristic properties.

\section{STATEMENT OF THE PROBLEM AND BASIC EQUATIONS}

Consider a cylindrical plasma solid-state waveguide with the radius $\rho_{0}$ occupying the region $0 \leq \rho \leq \rho_{0}$, $0 \leq \varphi \leq 2 \pi$, and $-\infty \leq z \leq+\infty$. The waveguide is located in free space in an external constant magnetic field, the vector $\vec{H}_{0}$ of which orientates parallel to its axial axis $Z$ of symmetry (Fig. 1). We assume that the plasma has high n-type conductivity. The density of conduction electron of a plasma is equal to $N_{0}$. The positively charged background of the crystal lattice of solid-state plasma compensates the negative charge of conduction electrons.

ISSN 1562-6016. BAHT. 2019. №4(122)

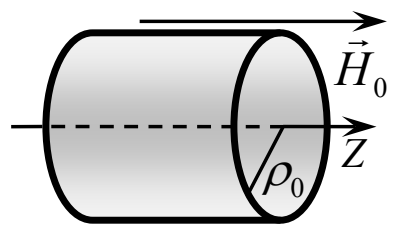

Fig. 1. Geometry of electrodynamic structure

Electromagnetic properties of media are described by the following system of equations

$$
\begin{aligned}
& \operatorname{rot} \vec{E}=-\frac{1}{c} \frac{\partial}{\partial t} \vec{H}, \\
& \operatorname{div} \vec{H}=0, \\
& \operatorname{rot} \vec{H}=\frac{4 \pi}{c} \vec{j}_{e}, \rho \leq \rho_{0}, \\
& \operatorname{rot} \vec{H}=-\frac{1}{c} \frac{\partial}{\partial t} \vec{E}, \rho>\rho_{0}, \\
& \overrightarrow{j_{e}}=e N_{0} \vec{u}, \\
& m v \vec{u}=e \vec{E}+\frac{e}{c}\left[\vec{u} \times \vec{H}_{0}\right],
\end{aligned}
$$

where $\vec{E}$ and $\vec{H}$ are the strengths of variable electric and magnetic fields, respectively, $\vec{j}_{e}$ is the density of current generated by the conduction electrons of solidstate plasma, $c$ is the velocity of light in free space, $\vec{u}$ is the electron velocity, $v$ is the collision frequency of electrons, $e$ and $m$ are the charge and effective mass of electron, respectively. In the linearized motion equation for conduction electrons (5) we have taken into account that $|\mathrm{d} \vec{u} / \mathrm{d} t|<<v|\vec{u}|$.

From equations (2) and (3) it follows that on the surface $\rho=\rho_{0}$ all components of the magnetic field are continuous, i.e. $\left.\vec{H}\right|_{\rho=\rho_{0}-0}=\left.\vec{H}\right|_{\rho=\rho_{0}+0}$. In this case, the boundary conditions for the electric field components are automatically satisfied.

After simultaneously consideration the equations (1) - (5), we obtain following equations for the components of magnetic field strength: 


$$
\frac{v}{\omega_{H}} \Delta \vec{H}+\frac{\partial}{\partial z} \operatorname{rot} \vec{H}-\frac{4 \pi e N_{0}}{c H_{0}} \frac{\partial}{\partial t} \vec{H}=0,
$$

where $\omega_{H}=e H_{0} / m c$ is the cyclotron frequency of conduction electrons, $\Delta=\Delta_{\perp}+\partial^{2} / \partial z^{2}$ is the Laplace operator, in which $\Delta_{\perp}=\frac{1}{\rho} \frac{\partial}{\partial \rho} \rho \frac{\partial}{\partial \rho}+\frac{1}{\rho^{2}} \frac{\partial^{2}}{\partial \phi^{2}}$. Taking into account that $\omega_{H}>>v$, the equation (6) can be represented as two equations:

$$
\begin{aligned}
& \frac{\partial}{\partial \mathrm{z}} \operatorname{rot} \vec{H}^{(1)}-\frac{4 \pi e N_{0}}{c H_{0}} \frac{\partial}{\partial t} \vec{H}^{(1)}=0, \\
& \operatorname{rot} \vec{H}^{(2)}-\frac{\omega_{H}}{v} \frac{\partial}{\partial z} \vec{H}^{(2)}=0 .
\end{aligned}
$$

The equation (7) describes the wave (oscillatory) processes of magnetic field when $v \rightarrow 0$ (i.e. helicon origin, for which $m \rightarrow 0$ [10]). The equation (8) describes the state of the magnetic field determined by the individual properties of conduction electrons $(m, e$, and $v$ ), when a collision frequency $v$ is finite. In this case $E_{z}^{(1)}=0$ and $\operatorname{rot} \vec{E}^{(2)}=0$. The solution of the equation (6) is a superposition of solutions of the (7) and (8) that is $\vec{H}=\vec{H}^{(1)}+\vec{H}^{(2)}$. The periodicities of the combined wave (oscillatory) processes characterized by the equation (6) are determined by the periodicities of the processes of helicon origin described by the equation (7).

\section{FIELDS OF NATURAL WAVES OF A PLASMA CYLINDER}

The electromagnetic field strength vectors of natural waves of a cylindrical plasma waveguide can be represented as

$$
\begin{aligned}
\vec{H} & =\sum_{n=-\infty}^{\infty} \vec{H}_{n}(\rho) \exp \left[i\left(q_{z} z+n \phi-\omega t\right),\right. \\
\vec{E} & =\sum_{n=-\infty}^{\infty} \vec{E}_{n}(\rho) \exp \left[i\left(q_{z} z+n \phi-\omega t\right),\right.
\end{aligned}
$$

where $q_{z}$ is the longitudinal (axial) wave number, $\omega=\omega^{\prime}-i \omega^{\prime \prime}$ is the wave frequency, and $\omega^{\prime \prime} \geq 0, n$ is the azimuthal mode index. In accordance with (6) - (8), the transverse spectral $H_{\rho n}(\rho)-$ and $H_{\varphi n}(\rho)$ components of magnetic field are determined through longitudinal components $H_{z n}^{(1)}(\rho)$ and $H_{z n}^{(2)}(\rho)$ of the partial waves, which are solutions of the equations

$$
\left(\Delta_{\perp}+\kappa_{1,2}^{2}\right) H_{z n}^{(1,2)}(\rho)=0
$$

where $\kappa_{1}^{2}=q_{1}^{2}-q_{z}^{2}$ and $\kappa_{2}^{2}=q_{2}^{2}-q_{z}^{2}$ are the squares of their transverse wave numbers, $q_{1}=4 \pi e \omega N_{0} / q_{z} c H_{0}$ and $q_{2}=-i q_{z} \omega_{H} / v$ are the wavenumbers of the helicons and partial additional waves, respectively. Note that $\kappa_{2}^{2}<0$. Equations (9) are the Bessel equation when $\kappa_{1} \in Z$ and the modified Bessel equations when $\kappa_{1}=i\left|\kappa_{1}\right|$ (i.e. $\kappa_{1}^{2}<0$ ) and $\kappa_{2}^{2}<0$.

Within the cylinder, taking into account the finiteness condition of the quantities $H_{z n}^{(1,2)}(\rho)$ at $\rho \rightarrow 0$, the solutions of (9) are

$$
\begin{gathered}
H_{z n}^{(1)}(\rho)=\left[\begin{array}{ll}
A_{n 1} J_{n}\left(\kappa_{1} \rho\right), & \kappa_{1} \in Z, \\
A_{n 1} I_{n}\left(\left|\kappa_{1}\right| \rho\right), & \kappa_{1}^{2}<0,
\end{array}\right. \\
H_{z n}^{(2)}(\rho)=A_{n 2} I_{n}\left(\left|\kappa_{2}\right| \rho\right),
\end{gathered}
$$

where $J_{n}(x)$ is the $n$th order Bessel function of the first kind, $I_{n}(x)$ is the modified function of the first kind (Infeld function), $A_{n 1}$ and $A_{n 2}$ are the arbitrary constants. Outside the cylinder, taking into account the finiteness condition of the quantities $H_{z n}(\rho)$ at $\rho \rightarrow \infty$ and the absence of charges in free space, the solutions of equation (9) have the form

$$
H_{z n}(\rho)=B_{n} K_{n}\left(\left|q_{z}\right| \rho\right),
$$

where $K_{n}(x)$ is the $n$th order modified function of the second kind (Macdonald function), $B_{n}$ is the arbitrary constant. According to (3) - (5), the longitudinal spectral components of electric field of the partial eigenwaves of waveguide at $\rho \leq \rho_{0}$ have the form

$$
\begin{gathered}
E_{z n}^{(1)}(\rho)=0, \\
E_{z n}^{(2)}(\rho)=i \frac{\omega}{q_{1} c} H_{z n}^{(2)}(\rho) .
\end{gathered}
$$

Outside the waveguide (at $\rho>\rho_{0}$ ), the $E_{z n}^{(2)}(\rho)$ components of electric field of the partial hybrid waves are determined by the solutions of the equation

$$
\left(\Delta_{\perp}-q_{z}^{2}\right) E_{z n}^{(2)}(\rho)=0 \text {. }
$$

Satisfying the finiteness condition of the quantities $E_{z n}^{(2)}(\rho)$ at $\rho \rightarrow \infty$, we have $E_{z n}^{(2)}(\rho)=C_{n} K_{n}\left(\left|q_{z}\right| \rho\right)$, where $C_{n}$ is the arbitrary constant.

According to (3) - (5) inside the cylinder $\left(\rho \leq \rho_{0}\right)$ and in accordance with $\rho \leq \rho_{0}$ outside of it $\left(\rho>\rho_{0}\right)$, the other electromagnetic field Fourier components of eigenwaves of the cylindrical waveguide are expressed in terms of $H_{z n}(\rho)$ - and $E_{z n}(\rho)$-components.

In accordance with the terminology of [11 - 14], in the case of $\kappa_{1} \in Z$, the electromagnetic fields of eigenwaves of the waveguide correspond to bulk-surface waves, whereas in the case of $\kappa_{1}^{2}<0$, they correspond to surface waves. Partial additional waves are surface hybrid waves. According to $E_{z n}^{(2)}(\rho)=i \omega H_{z n}^{(2)}(\rho) / q_{1} c$, taking into account the real values of the density of conduction electron of a solid-state plasma $\left(N_{0} \sim 10^{14} \ldots 10^{18} \mathrm{~cm}^{-3}[15]\right)$ and of the external magnetic field ( $\left.H_{0} \sim 1 \ldots 50 \mathrm{kGs}\right)$, they are $H$-type waves as $\left|E_{z n}^{(2)}(\rho)\right|_{\max }<\left|H_{z n}^{(2)}(\rho)\right|_{\max }$ [2]. Since the longitudinal component $E_{z}^{(1)}=0$, the partial helicon waves are $H$ waves. Consequently, the hybrid eigenwaves of a cylindrical plasma solid-state waveguide are $H$-type waves.

\section{DISPERSION EQUATIONS}

Satisfying the boundary conditions on the cylinder surface $\rho=\rho_{0}$, we obtain the following dispersion equation for the bulk-surface eigenwaves of a cylindrical plasma waveguide: 


$$
\begin{aligned}
& \left(\frac{\left|q_{z}\right|}{q_{z}} \frac{K_{n}^{\prime}\left(\left|q_{z}\right| \rho_{0}\right)}{K_{n}\left(\left|q_{z}\right| \rho_{0}\right)}+\frac{q_{z}}{\kappa_{1}} \frac{J_{n}^{\prime}\left(\kappa_{1} \rho_{0}\right)}{J_{n}\left(\kappa_{1} \rho_{0}\right)}-\frac{n q_{1}}{\kappa_{1}^{2} \rho_{0}}\right) \times \\
& \times\left(\frac{n q_{2}^{2}}{\left|\kappa_{2}^{2}\right| q_{z} \rho_{0}}-\frac{q_{2}}{\left|\kappa_{2}\right|} \frac{I_{n}^{\prime}\left(\left|\kappa_{2}\right| \rho_{0}\right)}{I_{n}\left(\left|\kappa_{2}\right| \rho_{0}\right)}\right)- \\
& -\left(\frac{q_{1}}{\kappa_{1}} \frac{J_{n}^{\prime}\left(\kappa_{1} \rho_{0}\right)}{J_{n}\left(\kappa_{1} \rho_{0}\right)}-\frac{n q_{1}^{2}}{\kappa_{1}^{2} q_{z} \rho_{0}}\right)\left(\frac{\left|q_{z}\right|}{q_{z}} \frac{K_{n}^{\prime}\left(\left|q_{z}\right| \rho_{0}\right)}{K_{n}\left(\left|q_{z}\right| \rho_{0}\right)}-\right. \\
& \left.-\frac{q_{z}}{\left|\kappa_{2}\right|} \frac{I_{n}^{\prime}\left(\left|\kappa_{2}\right| \rho_{0}\right)}{I_{n}\left(\left|\kappa_{2}\right| \rho_{0}\right)}+\frac{n q_{2}}{\left|\kappa_{2}^{2}\right| \rho_{0}}\right)=0 .
\end{aligned}
$$

For surface waves for which $\kappa_{1}^{2}=-\left|\kappa_{1}^{2}\right|$, in equation (10) the function $J_{n}\left(\kappa_{1} \rho_{0}\right) / \kappa_{1} J_{n}^{\prime}\left(\kappa_{1} \rho_{0}\right)$ acquire the form $-I_{n}\left(\left|\kappa_{1}\right| \rho_{0}\right) /\left|\kappa_{1}\right| I_{n}^{\prime}\left(\left|\kappa_{1}\right| \rho_{0}\right)$. The primed cylindrical functions denote their derivatives with respect to the argument. The solutions of equation (10) determine the frequencies $\omega_{n s}$ and wave numbers $q_{z n s}$ of the hybrid eigenmodes of a cylindrical waveguide. The module of the azimuthal mode index $|n|$ corresponds to half the number of field variations in the angle $\varphi$. When $n=0$, we have symmetric modes. The radial index $s$ corresponds to the root order number of the dispersion equation (when the roots are arranged in order of increasing frequency) and represents the number of field variations along the radial coordinate $\rho$.

It is obvious that solutions of (10) for modes with identical field distributions, but differing in the sign of the azimuthal index, do not coincide. In addition, their solutions for different directions of the external magnetic field, which differ in phase on $\pi$, do not also coincide. This indicates that the eigenwaves propagating in opposite directions along the azimuthal coordinate have different phase velocities $\left(\omega_{n s} / q_{z n s}\right)$. This is the demonstration of the nonreciprocity effect of the propagation of eigenwaves of a plasma cylinder located in a strong longitudinal magnetic field. This nonreciprocity effect leads to the removal of the frequency degeneracy in the azimuthal index. The nonreciprocity of the eigenwaves, associated with the direction of $\vec{H}_{0}$, is substantiated by the opposite directions of rotation of conduction electrons of a solid-state plasma in an external magnetic field.

In the case of a collisionless solid-state plasma $(v=0)$, the bulk-surface helicons exist in the waveguide. In this case, equation (10) takes the form

$$
\left(\frac{\left|q_{z}\right|}{q_{z}} \frac{K_{n}^{\prime}\left(\left|q_{z}\right| \rho_{0}\right)}{K_{n}\left(\left|q_{z}\right| \rho_{0}\right)}+\frac{q_{z}}{\kappa_{1}} \frac{J_{n}^{\prime}\left(\kappa_{1} \rho_{0}\right)}{J_{n}\left(\kappa_{1} \rho_{0}\right)}-\frac{n q_{1}}{\kappa_{1}^{2} \rho_{0}}\right)=0
$$

The solutions of equation (11) determine the spectrum of bulk-surface helicon waves. Obviously, in a collisionless plasma waveguide of a cylindrical configuration the surface helium modes do not exist because of the absence of solutions of the dispersion equation (10) at $\kappa_{1}^{2}=-\left|\kappa_{1}^{2}\right|$ and $v=0$.

We note that dispersion equation (11) can be obtained from the direct consideration of a collisionless plasma cylinder located in a strong external magnetic field. In this case, the $H_{\rho}$ - and $H_{z}$-components of magnetic field are continuous on the cylinder surface $\rho=\rho_{0}$, and the $H_{\varphi}$-component is discontinuous due to the longitudinal surface current, i.e. $H_{\varphi}\left(\rho_{0}+0\right)-H_{\varphi}\left(\rho_{0}-0\right)=4 \pi j_{s z} / c$, where $j_{s z}$ is the density of longitudinal surface current. The boundary conditions for the electric field components do not change.

Thus, in the absence of charge-carrier collisions the bulk-surface helicons exist only in a plasma waveguide. Their propagation is accompanied by a surface current flowing along the elements of cylinder. Collisions of charged particles destroy the surface current and lead to the formation of additional $H$-type hybrid waves, which transmit changes in the state of the magnetic field. In this case, the phase velocities coincide for the spectral components of the helicons and the additional hybrid waves. Field localizations of the weakly decaying spectral components of eigenwaves, for which $|n|>>1$, are concentrated near the side surface of the waveguide.

\section{NUMERICAL ANALYSIS OF THE DISPERSION EQUATIONS}

The dispersion equations (10) and (11) have dimensionless forms, which emphasize their universality. The dimensionless form of the waveguide eigenfrequencies is provided by their normalization to the characteristic frequency $\omega_{0}=c / \rho_{0}$, taking into account the identity of the cylindrical waveguide configuration.

We investigated the conducting cylindrical solidstate waveguide with the characteristic frequency $\omega_{0}=1.2 \cdot 10^{11} \mathrm{~s}^{-1}$, which corresponds to the radius $\rho_{0}=0.25 \mathrm{~cm}$. The following materials were used as the waveguide material: $a$ ) the collisionless solid-state single-component plasma with electron concentration $\left.N_{0}=10^{14} \mathrm{~cm}^{-3} ; b\right)$ the indium antimonide with electronic conductivity (n-InSb), in which $N_{0}=2.7 \cdot 10^{14} \mathrm{~cm}^{-3}$ and $v=10^{12} \mathrm{~s}^{-1}$. In both materials the effective electron mass $m=0.013 m_{0}$, where $m_{0}$ is the free electron mass. The waveguide was located in the uniform longitudinal magnetic field $H_{0}=8 \mathrm{kGs}$.

Fig. 2 shows the dispersion dependences of the bulksurface symmetric $H_{0 s}(s=1,2)$ and hybrid $E H_{n s}$ ( $n= \pm 1, \pm 2 ; s=1,2$ ) eigenmodes of the conducting cylinder made of collisionless solid-state plasma $(a)$ or indium antimonide $(b)$. The parameters of the eigen helicons of the collisionless plasma waveguide satisfy the equation (11), and the eigenwaves of the $\mathrm{n}$-InSb waveguide satisfy the equation (10). Line 1 corresponds to the dependence $\kappa_{1}=0$ and separates the regions of bulk-surface and surface waves.

As seen from Fig. 2, the modes with identical field distributions, but differing in sign of the azimuthal index, have different phase velocities. This causes the nonreciprocity of their propagation in the waveguides under study.

As numerical analysis showed, the nondimensional imaginary parts of frequencies $\left(\omega_{n s}^{\prime \prime} / \omega_{0}\right)$ of the bulksurface waves do not exceed the value of $10^{-2}$ in a semiconductor waveguide. With an increase in both the lon- 
gitudinal wave number $q_{z}$ (with a constant waveguide radius $\rho_{0}$ ) and the modulus of azimuthal index $|n|$ the ratio $\omega_{n s}^{\prime \prime} / \omega_{0}$ (with a constant $s$ ) decreases, and the Qfactors of waveguide increase.
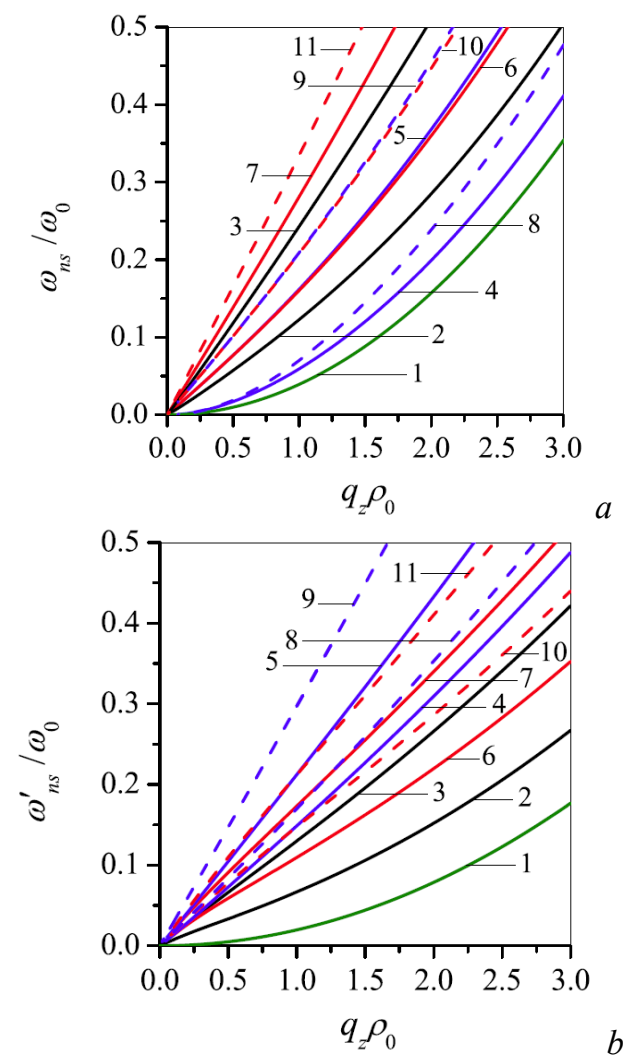

Fig. 2. Dispersion dependences of the bulk-surface symmetric $\left[H_{01}\right.$ (2) and $H_{02}$ (3)] and hybrid

$\left[E H_{-11}\right.$ (4), $E H_{-12}$ (5), $E H_{11}$ (6), $E H_{12}$ (7), $E H_{-21}$ (8),

$E H_{-22}$ (9), $E H_{21}$ (10), and $E H_{22}$ (11)] eigenmodes

of the collisionless plasma (a) or n-InSb (b) cylinder;

$$
1 \text { - bounding line } \kappa_{1}=0
$$

When $|n|>>1$, there are weakly decaying bulk-surface waves of helicon origin in a waveguide. In the case of surface waves the ratios of $\omega_{n s}^{\prime} / \omega_{0}$ have small values, and the ratios of $\omega_{n s}^{\prime \prime} / \omega_{0}$ have large values, which indicates their strongly decaying relaxation character.

\section{CONCLUSIONS}

In this paper, the properties of natural waves of a cylindrical solid-state plasma waveguide located in a strong longitudinal magnetic field are theoretically studied. It is revealed that the natural waves of the waveguide are formed by the superposition of partial helium waves and additional hybrid waves, the frequency dependence of which is only contained in the multiplier $\exp (-i \omega t)$. It is established that in a collisionless plasma cylinder there are only bulk-surface helicons. Their propagation is accompanied by surface current, which flows along the elements of cylinder. Collisions of charged particles destroy the surface current and lead to the formation of additional $H$-type hybrid waves. In a solid-state plasma cylinder, the effect of nonreciprocal propagation of its eigenwaves with identical field distri- bution structures, but differing in the direction of propagation along the azimuthal coordinate, has been found out. The nonreciprocity effect of the eigenwaves of waveguide exists also in case of different directions of the external magnetic field, which differ in phase on $\pi$.

\section{REFERENCES}

1. A. Barannik, N. Cherpak, A. Kirichenko, Yu. Prokopenko, S. Vitusevich, V. Yakovenko. Whispering gallery mode resonators in microwave physics and technologies // Int. Journal of microwave and wireless technologies. 2017, v. 9, Issue 4, p. 781-796.

2. A.Ya. Kirichenko, Yu.V. Prokopenko, Yu.F. Filippov, N.T. Cherpak. Quasi-optical solid-state resonators. Kiev: "Naukova dumka", 2008, 286 p. (in Ukrainian).

3. E.A. Kaner, V.G. Skobov. Electromagnetic waves in metals in a magnetic field // Sov. Phys. Usp. 1967, v. 9, Issue 4, p. 480-503.

4. B.W. Maxfield Helicon Waves in Solids // Amer. J. Phys. 1969, v. 37, p. 241.

5. E.A. Kaner Helicon. Physical encyclopedia. v. 1. M.: "Soviet encyclopedia", 1988, 428 p.

6. O.V. Konstantinov and V.I. Perel'. Possible transmission of electromagnetic waves through a metal in a strong magnetic field // Soviet Physics JETP. 1960, v. 11, Issue 1, p. 117-119.

7. P. Aigrain. Les "Helicons" dans les semiconducteurs // Proc. Int. Conf. on Semiconduction Phys. Prague, 1960, p. 224.

8. R. Bowers, C. Legendy, and F. Rose Oscillatory Galvanomagnetic Effect in Metallic Sodium // Phys. Rev. Lett. 1961. v. 7, Issue 9, p. 339-341.

9. L.D. Landau, E.M. Lifshits. Theoretical physics. V. 8. Electrodynamics of continuous media. M.: "Science", 1982, 620 p. (in Russian).

10. N.N. Beletskiy, V.M. Svetlichniy, D.D. Khalameyda, V. M. Yakovenko. Electromagnetic phenomena of microwave in inhomogeneous semiconductor structures. Kiev: "Naukova dumka", 1991, 215 p. (in Ukrainian).

11. M.V. Kuzelev, A.A. Rukhadze, and P.S. Strelkov. Plasma relativistic microwave electronics. M.: Publishing House of the N. E. Bauman Moscow State Technical University, 2002, 544 p.

12. Yu.O. Averkov, Yu.V. Prokopenko, V.M. Yakovenko. Eigenwave Spectra of an Anisotropic Cylindrical Solid-State Waveguide // Technical Physics. 2019, v. 64, Issue 1, p. 5-11.

13. Yu.O. Averkov, Yu.V. Prokopenko, V.M. Yakovenko. Interaction between a tubular beam of charged particles and an anisotropic dispersive solid-state cylinder // Problems of Atomic Science and Technology. Series "Plasma Electronics and New Methods of Acceleration”. 2018, № 4, p. 3-12.

14. Yu.O. Averkov, Yu.V. Prokopenko, V.M. Yakovenko. Interaction between a tubular beam of charged particles and a dispersive metamaterial of cylindrical configuration // Physical Review E. 2017, v. 96, Issue 1, p. 013205(12).

15. Fizicheskaya enciklopediya / Pod red. A.M. Prohorova. M.: Nauch. isd. "Bolshaya rossijskaya enciklopediya ", 1994, 704 p. (in Russian).

Article received 10.06.2019 


\section{ГЕЛИКОНЫ В ПЛАЗМЕННОМ ТВЕРДОТЕЛЬНОМ ВОЛНОВОДЕ ЦИЛИНДРИЧЕСКОЙ КОНФИГУРАЦИИ}

\section{Ю.О. Аверков, Ю.В. Прокопенко, В.М. Яковенко}

Построена теория собственных электромагнитных волн цилиндрического плазменного волновода, расположенного в постоянном продольном магнитном поле. Получено дисперсионное уравнение в условиях, когда отношение частоты столкновений основных носителей заряда к их циклотронной частоте много меньше единицы. Показано, что в плазменном волноводе существуют объёмно-поверхностные геликоны. Их распространение в отсутствие столкновений носителей заряда сопровождается поверхностным током, направленным параллельно продольной оси симметрии цилиндра. Столкновения заряженных частиц разрушают поверхностный ток и приводят к образованию дополнительных гибридных волн $H$-типа, локализации полей которых сосредоточены вблизи боковой поверхности волновода. Обнаружен эффект невзаимности собственных волн, отличающихся направлением распространения по азимутальной координате, а также при изменении направления внешнего магнитного поля.

\section{ГЕЛІКОНИ В ПЛАЗМОВОМУ ТВЕРДОТІЛЬНОМУ ХВИЛЕВОДІ ЦИЛІНДРИЧНОї КОНФІГУРАЦІї}

\section{Ю.О. Аверков, Ю.В. Прокопенко, В.М. Яковенко}

Побудовано теорію власних електромагнітних хвиль циліндричного плазмового хвилеводу, який розташовано в постійному поздовжньому магнітному полі. Отримано дисперсійне рівняння в умовах, коли відношення частоти зіткнень основних носіїв заряду до їх циклотронної частоти багато менше одиниці. Показано, що в плазмовому хвилеводі існують об'ємно-поверхневі гелікони. Їх поширення у відсутності зіткнень носіїв заряду супроводжується поверхневим струмом, який спрямований паралельно поздовжній осі симетрії циліндра. Зіткнення заряджених частинок руйнують поверхневий струм і призводять до утворення додаткових гібридних хвиль $H$-типу, локалізації полів яких зосереджені поблизу бокової поверхні хвилеводу. Виявлено ефект невзаємності власних хвиль, що відрізняються напрямком поширення за азимутальною координатою, а також при зміні напрямку зовнішнього магнітного поля. 